\title{
MODELING AND SIMULATION OF STATCOM FOR POWER QUALITY IMPROVEMENT
}

\author{
Ch. Umamaheswararao ${ }^{1}$, A.Sriharibabu ${ }^{2 *}$, J. Jithendranath ${ }^{3}$, A.R. Vijay Babu ${ }^{4}$ \\ ${ }^{1.2 .4}$ Department of Electrical \& Electronics Engineering, Vignan's Foundation for Science, Technology \& \\ Research, Vadlamudi, India \\ ${ }^{3}$ Department of Electrical \& Electronics Engineering, Global Academy of Technology, Bangalore, India \\ *sriharielectrical@gmail.com
}

\begin{abstract}
In power system, reactive power compensation is one of the important action to maintain better voltage profile, stability and decrease losses. STATCOM is feasible in terms of cost effective in wide range of problem solving capabilities among all Flexible AC Transmission system (FACTS) in both transmission and distribution levels. In this paper the synchronous rotating frame theory algorithm is used since it is easy to implement i.e. the rotating three phase quantities are converted into stationary components. So it requires less number of PI controllers and also calculations on the stationary quantities are easy than to do calculations on instantaneous quantities and the modeling of STATCOM is done. This project focuses on improvement of power quality in a three phase three wire system with a non-linear load i.e., three phase bridge rectifier and a parallel inductive load. Some power quality aspects like reactive power compensation of linear load, better Total Harmonic Distortion (THD) performance and the power factor improvement are achieved. The result shows the THD of input current achieved as per the IEEE 519. 1992 standard. It is observed that STATCOM gives effective compensation for reactive power variation and hence the power quality of distribution systems improved.
\end{abstract}

Keywords: Total Harmonic Distortion (THD), STATCOM, Reactive power

\section{Introduction}

In the late $19^{\text {th }}$ century, the reactive power unbalance problem causing deviation in voltage and power transfer limitation during load change were observed. Now days, these problems have even great impact on secure and reliable power supply in the view of privatization and globalization of electrical systems and energy transfer. The complex tasks like load flow control and power transmission to be improved by using reliable and fast semiconducting devices (IGBT and GTO) by using modern power electronic configuration in power system networks.

Cost effective elucidation for the reactive power compensation and load unbalance in transmission system can be effectively achieved by using STATCOM among other FACTS devices.

The STATCOM performance is based on the control algorithm i.e. the extraction of the current components from specified power system network. To obtain this, there are several control schemes like IRP theory (Instantaneous Reactive Power), SRF (Synchronous Rotating Frame) theory, instantaneous

Copyright $($ ) Authors symmetrical components, instantaneous compensation, computation based on per phase basis and method based on neural network. IRP theory is most widely used among mentioned control schemes. This work focuses on the compensating the reactive power and THD reduction to a possible minimum percentage of value. The analysis of dynamic performance is obtained and verified through simulation. The main objective of this paper is to implement STATCOM with a control strategy to maintain power quality with high standards. As well as minimizing THD to less value and also improving power factor are targeted.

\section{Static Synchronous Compensator}

The additional investment burden on industries to achieve reliability and power quality requires high amount mainly due to voltage sags, distorted and unwanted voltage wave forms and short-term interruptions. The reliability of power supply is the main requirement for the electricity consumers. The reliability is the power supply continuity. The problem in distribution lines is classified into two 
types as shown in Fig. 1. First type is power reliability and second is power quality. First type consists of voltage sags and outages. Second type consists of impulses and swells, and harmonic distortions. Voltage sags are severe trouble as its effect may force to huge amount of damage to the system. If voltage sag exceed a hardly any cycle, robots, motors, machine tools and servo drives cannot preserve control of progression

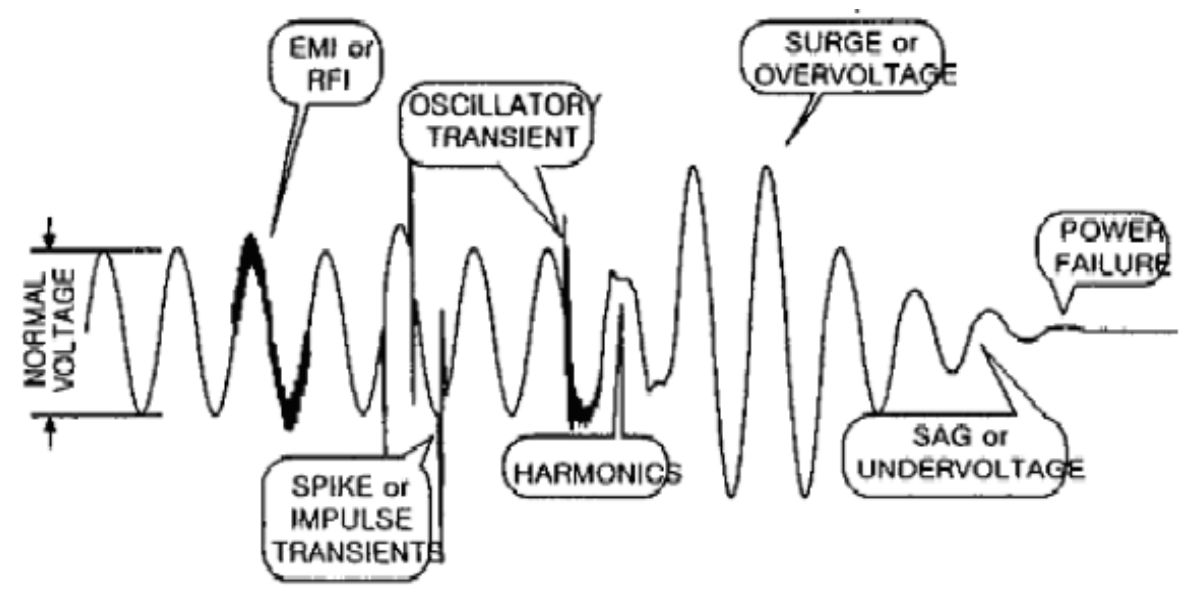

Fig.1. Power Quality and Reliability

\subsection{Importance of Reactive Power and THD}

When an alternating voltage and current both rise or fall at the same particular instant, then active power flows in transmission system. And if there is a time lag between current and voltage, then both active and reactive powers will exist and flows in transmission system. THD is a complex and often mystifying concept in power system analysis. However, it is easier to understand when it broken down into the basic definitions of distortion and harmonics. Visualize a power system with an electrical load and an AC source as shown in Fig. 2

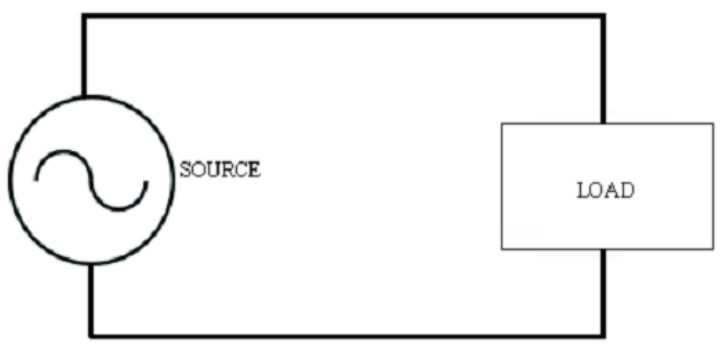

Fig. 1. Power System with AC Source and Electrical Load

Wave forms of voltage and current for linear loads is as shown in fig. 3 


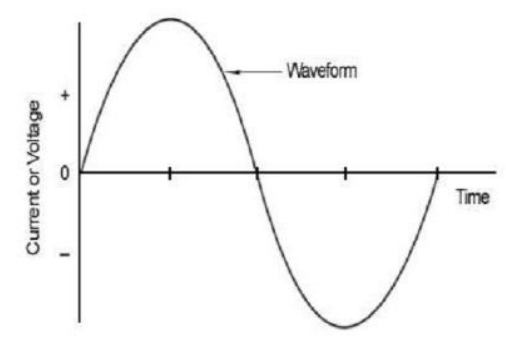

Fig. 2. Ideal Sine wave

For linear loads the wave form becomes non sinusoidal nature with harmonics as shown in fig. 4

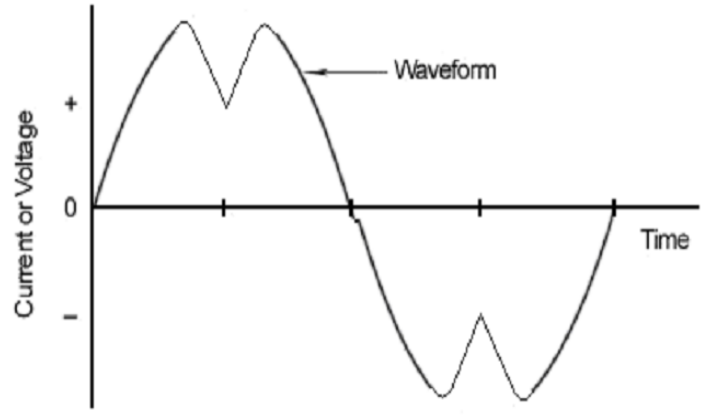

Fig.3. Distorted Waveform

\section{FACTS Controllers}

The FACTS controllers' development used two different methods to implement. The first method is by using a tap changing transformer and the second method is by using voltage sources realized by static converters with self-commutation. On the whole these are three categories

\subsection{Distribution System}

3.1 STATCOM:STATCOM is the best method for reactive power compensation. It has certain advantages like independent of PCC voltage as not possible in other methods. Voltage profile can be maintained and also the power factor can be improved by using STATCOM. Basically It operates in three modes called inductive, capacitive and ideal modes to provide required reactive power to inject into a specified power system. Hence, it is the preferred method for maintaining the power quality. The STATCOM is used for the correction of bus voltage sags by using voltage source inverter topology based static compensator. The STATCOM generates endlessly variable capacitive or inductive shunt compensations up to an extent of its peak MVA rating. The line waveform is continuously monitored by STATCOM with regard to a reference ac signal. If any deviation between two wave forms, then it provides the proper magnitude of lagging or leading reactive current compensation to decrease the amount of voltage fluctuations.

\subsection{STATCOM Components:}

It consists of three components and they are

- GTO or IGBT based DC - AC Inverter.

- $\quad$ L-C filter

- Control block

3.3 Operating Principle:The STATCOM system contains three main blocks; those are VSC, a set of step-up transformers or coupling reactors and controller. This controller is placed with very-highvoltage coupling reactors or a step-up power transformers is shown in Fig. 5. 


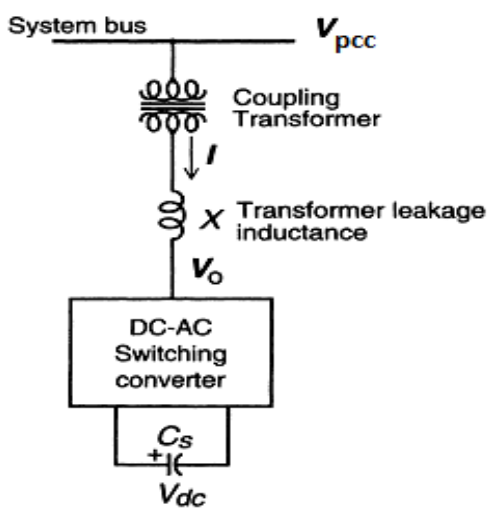

Fig.4. Block Diagram of STATCOM

STATCOM in capacitive mode is operated to inject reactive power i.e. VAR generation (-Q) by setting converter voltage is greater than voltage at PCC. As well as, inductive mode of STATCOM can be operated by setting up the converter voltage as less as compared to PCC voltage to absorb the reactive power $(+Q)$ from grid which excess flowing at a particular instant in a power system network. These modes are included in the Fig. 6

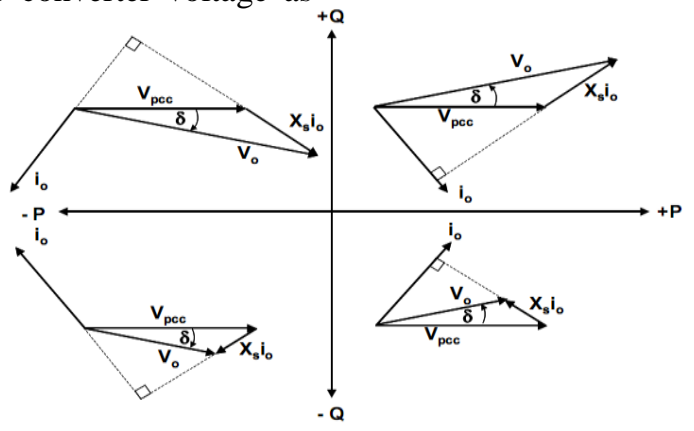

Fig. 5. Phasor Diagram for Exchanging in STATCOM

The basic voltage and current waveforms in three operating modes of STATCOM are shown in Fig.7. If the operating load is inductive nature and it demands reactive power from grid. Then the STATCOM generates the reactive power by setting the voltage wave forms as in Fig.7. The STATCOM acts as a sink for reactive power to absorb the excess amount by setting appropriate magnitude and phase angle of voltage. And in third mode is ideal mode as there is no injection and absorption of reactive power. The waveforms of Voltage Source are shown in Fig. 8

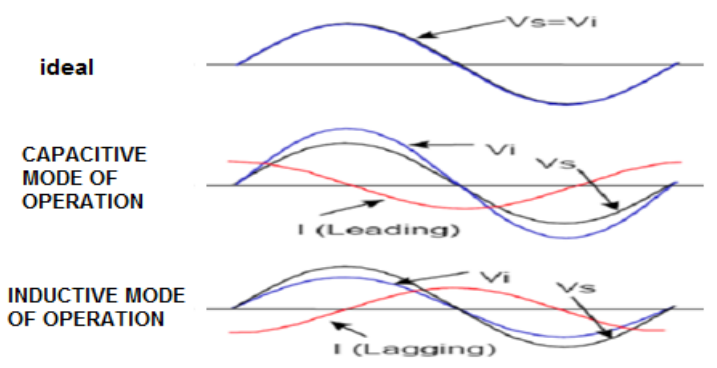

Fig. 6. STATCOM's three operating modes 


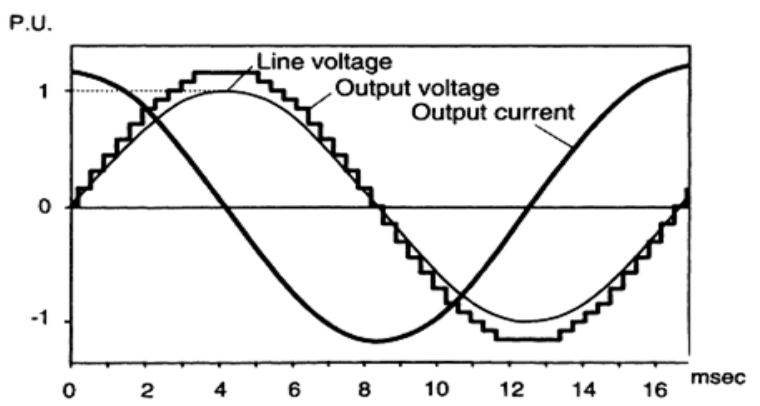

Fig. 7. Typical output voltage and current of Voltage Source Converter
3.4. V-I Characteristics of STATCOM: The
voltage proportionately when system voltage STATCOM operates its voltage in the limits from $\mathrm{V}_{1}$ to $\mathrm{V}_{2}$ smoothly and continuously as shown in Fig. 9. tolerates in between a lower-voltage $\left(\mathrm{V}_{1}\right)$ and higher-voltage limit $\left(\mathrm{V}_{2}\right)$. Moreover, the STATCOM on timely basis function as a constant current source by varying the converter

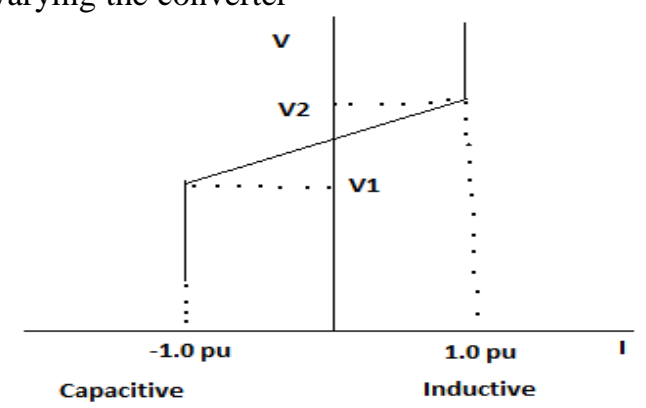

Fig.8. V-I Characteristics of STATCOM

3.5. Basic Control Approach: The external system control provides the reference signals through operator commands and system variables. It enroots the efficient operation of the STATCOM as per loadings on the grid. The internal control reaches the target basically by 2 components. First one is by estimating the magnitude and phase angle of the targeted output voltage from reactive current component which is generated by the external control. Second component is by producing a set of synchronized timing waveforms as shown in Fig. 10. These components determine the $\mathrm{ON}$ and $\mathrm{OFF}$ periods of each element in converter block matching to the required output voltage.
These waveforms generated on timely basis contain phase relationship between two voltages. This phase relationship depends on the sytem used for getting the output voltage waveform, the converter level or pulse number and the three output voltages with necessary angular phase relationship. The internal key parameters of magnitude and angle of the output voltage will derive the real and reactive current of converter draws and finally optimizes real and reactive power to be exchanged with the ac system 


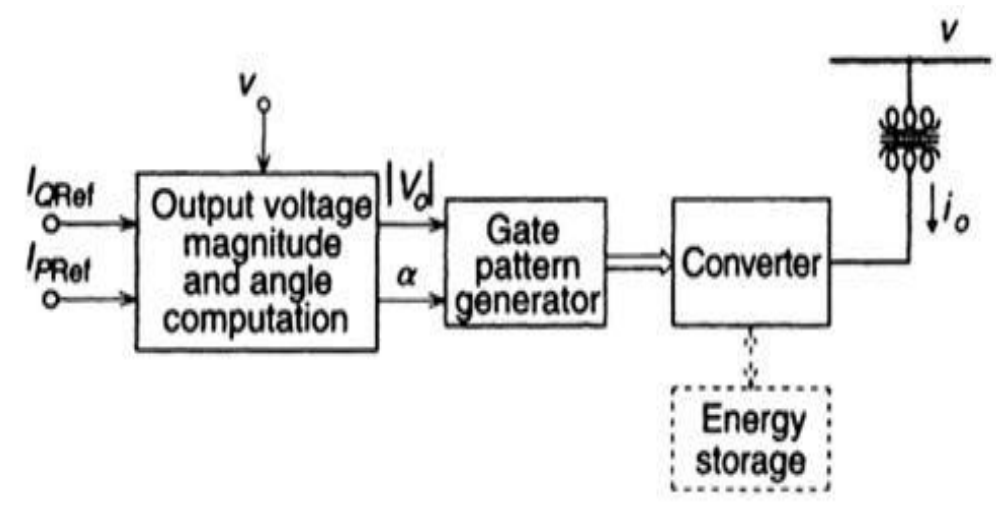

Fig.9. Main Function of the Internal Converter Control

\section{Control Algorithm for STATCOM}

The major objective of a compensation method is to have flexibility, fast response and simple to put into practice. The implementation of control algorithms of STATCOM are mostly done by the following steps

- Measurements of system currents and voltages

- Signal programming

- computation of compensating signals

- creation of switching device firing angles.

Various types of control strategies of STATCOM are as follows.
- Synchronous Rotating Frame Method (SRFT)

- Decoupled Current Control

- Phase Shift Control

- Adaline Based Control Algorithm

- Regulation of Bus and DC Voltage

\subsection{Synchronous Rotating Frame Theory}

The SRFT (Synchronous Rotating Frame Method) is basically works on the transformation/conversion of the currents $d-q$ frame which runs synchronously. Fig.11explains the basic structure blocks of SRFT. If transformation angle $\theta$ is to be obtained, then the currents conversion from $\alpha-\beta$ to $d-q$ frame and is written as

$$
\left[\begin{array}{l}
i_{d} \\
i_{q}
\end{array}\right]=\left[\begin{array}{cc}
\cos \theta & \sin \theta \\
-\sin \theta & \cos \theta
\end{array}\right]\left[\begin{array}{l}
i_{\alpha} \\
i_{\beta}
\end{array}\right]
$$




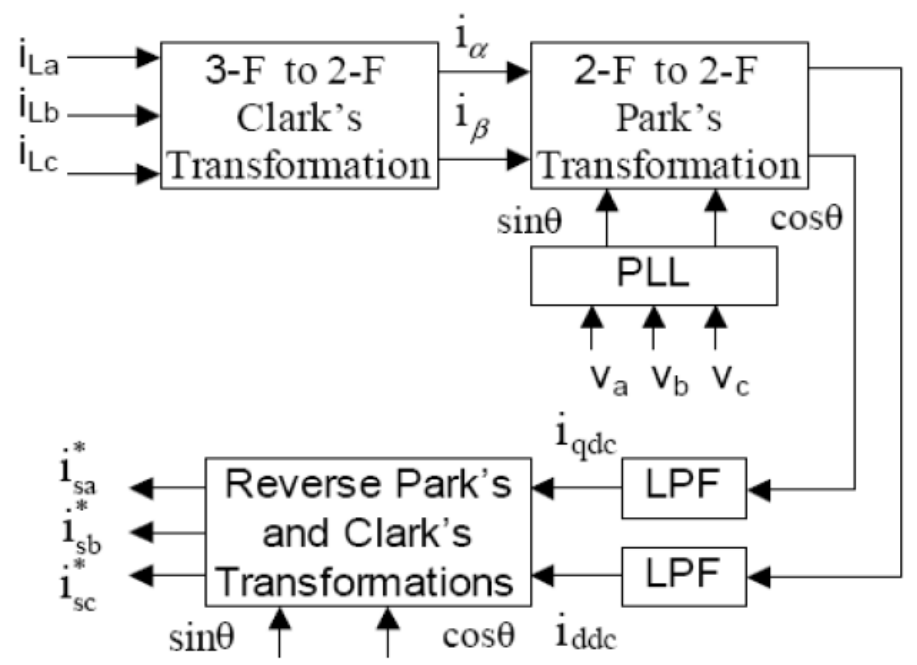

Fig.10. Block Diagram of Synchronous Rotating Frame Theory Based Control of STATCOM

SRF isolator extracts the dc component by using Low Pass Filters (LPF) for each $\mathrm{I}_{\mathrm{d}}$ and $\mathrm{I}_{\mathrm{q}}$. This sampling is realized by oscillating at an

$$
\left[\begin{array}{l}
i_{\alpha d c} \\
i_{\beta d c}
\end{array}\right]=\left[\begin{array}{c}
\cos \theta \\
-\sin \theta
\end{array}\right.
$$

Three phase basic reference currents are obtained in a--b--c coordinates by transformation. In this work SFR control theory is used because of its simplicity and flexibility to

\section{Modeling of STATCOM Controller}

The basic circuit of a grid-connected VSC is pointed in Fig. 12. The VSC and the grid are modeled as L-filter and two three-phase voltage sources. L-element each one in every phase is connected in series between grid and VSC. The average of $100 \mathrm{~Hz}$. The absorbed DC components such as $i_{d d c}$ and $i_{q d c}$ are converted into $\alpha-\beta$ by using expression below.

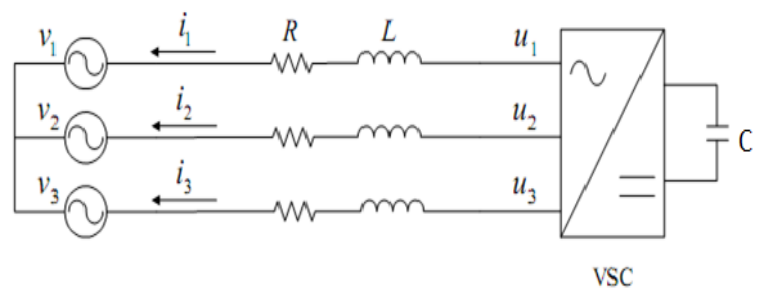

Fig.11. Grid-connected VSC simplified Circuit

Vector diagram of three phase supply is as exposed in Fig.13 inputs of VSC phase voltages represented as $\mathrm{u}_{1}(\mathrm{t})$,
$\mathrm{u}_{2}(\mathrm{t})$ and $\mathrm{u}_{3}(\mathrm{t})$. The grid phase voltages are
represented as $\mathrm{V}_{1}(\mathrm{t}), \mathrm{V}_{2}(\mathrm{t})$ and $\mathrm{V}_{3}(\mathrm{t})$. The phase
currents in each filter are represented as $\mathrm{i}_{1}(\mathrm{t}), \mathrm{i}_{2}(\mathrm{t})$
and $\mathrm{i}_{3}(\mathrm{t})$. The equivalent coil parameters of the Linputs of VSC phase voltages represented as $\mathrm{u}_{1}(\mathrm{t})$,
$\mathrm{u}_{2}(\mathrm{t})$ and $\mathrm{u}_{3}(\mathrm{t})$. The grid phase voltages are
represented as $\mathrm{V}_{1}(\mathrm{t}), \mathrm{V}_{2}(\mathrm{t})$ and $\mathrm{V}_{3}(\mathrm{t})$. The phase
currents in each filter are represented as $\mathrm{i}_{1}(\mathrm{t}), \mathrm{i}_{2}(\mathrm{t})$
and $\mathrm{i}_{3}(\mathrm{t})$. The equivalent coil parameters of the Linputs of VSC phase voltages represented as $\mathrm{u}_{1}(\mathrm{t})$,
$\mathrm{u}_{2}(\mathrm{t})$ and $\mathrm{u}_{3}(\mathrm{t})$. The grid phase voltages are
represented as $\mathrm{V}_{1}(\mathrm{t}), \mathrm{V}_{2}(\mathrm{t})$ and $\mathrm{V}_{3}(\mathrm{t})$. The phase
currents in each filter are represented as $\mathrm{i}_{1}(\mathrm{t}), \mathrm{i}_{2}(\mathrm{t})$
and $\mathrm{i}_{3}(\mathrm{t})$. The equivalent coil parameters of the Linputs of VSC phase voltages represented as $\mathrm{u}_{1}(\mathrm{t})$,
$\mathrm{u}_{2}(\mathrm{t})$ and $\mathrm{u}_{3}(\mathrm{t})$. The grid phase voltages are
represented as $\mathrm{V}_{1}(\mathrm{t}), \mathrm{V}_{2}(\mathrm{t})$ and $\mathrm{V}_{3}(\mathrm{t})$. The phase
currents in each filter are represented as $\mathrm{i}_{1}(\mathrm{t}), \mathrm{i}_{2}(\mathrm{t})$
and $\mathrm{i}_{3}(\mathrm{t})$. The equivalent coil parameters of the Linputs of VSC phase voltages represented as $\mathrm{u}_{1}(\mathrm{t})$,
$\mathrm{u}_{2}(\mathrm{t})$ and $\mathrm{u}_{3}(\mathrm{t})$. The grid phase voltages are
represented as $\mathrm{V}_{1}(\mathrm{t}), \mathrm{V}_{2}(\mathrm{t})$ and $\mathrm{V}_{3}(\mathrm{t})$. The phase
currents in each filter are represented as $\mathrm{i}_{1}(\mathrm{t}), \mathrm{i}_{2}(\mathrm{t})$
and $\mathrm{i}_{3}(\mathrm{t})$. The equivalent coil parameters of the Lfilter are represented as L and R, respectively. $\sin \theta]\left[\begin{array}{l}i_{\text {ddc }} \\ i_{\text {qdc }}\end{array}\right]$
$\cos \theta$
implement hardware i.e. it require less number of
PI controllers and it is simple to do calculations
on stationary quantities than to do on
instantaneous $\sin \theta]\left[\begin{array}{l}i_{\text {ddc }} \\ i_{\text {qdc }}\end{array}\right]$
$\cos \theta$
implement hardware i.e. it require less number of
PI controllers and it is simple to do calculations
on stationary quantities than to do on
instantaneous $\sin \theta]\left[\begin{array}{l}i_{\text {ddc }} \\ i_{\text {qdc }}\end{array}\right]$
$\cos \theta$
implement hardware i.e. it require less number of
PI controllers and it is simple to do calculations
on stationary quantities than to do on
instantaneous $\sin \theta]\left[\begin{array}{l}i_{\text {ddc }} \\ i_{\text {qdc }}\end{array}\right]$
$\cos \theta$
implement hardware i.e. it require less number of
PI controllers and it is simple to do calculations
on stationary quantities than to do on
instantaneous 


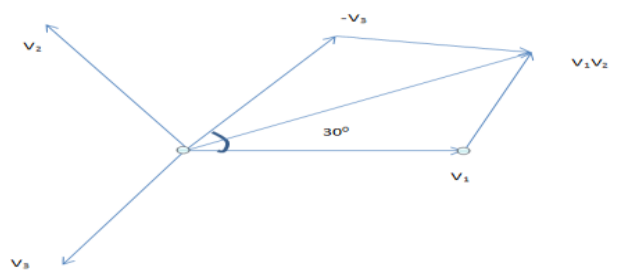

Fig.12. Vector Diagram of Three Phase Supply

The Instantaneous grid voltage equations are

$$
\begin{aligned}
& \mathrm{V}_{1}=\sqrt{\frac{2}{3}} V \cos (\omega t) \\
& \mathrm{V}_{2}=\sqrt{\frac{2}{3}} V \cos \left(\omega t-\frac{2}{3} \pi\right) \\
& \mathrm{V}_{3}=\sqrt{\frac{2}{3}} V \cos \left(\omega t-\frac{4}{3} \pi\right)
\end{aligned}
$$

The system state space equations in $\alpha \beta$-frame can be written as

$$
\begin{aligned}
& {\left[\begin{array}{c}
\frac{d i_{\alpha}(t)}{d x} \\
\frac{d i_{\beta}(t)}{d x}
\end{array}\right]=\left[\begin{array}{cc}
\frac{-R}{L} & 0 \\
0 & \frac{-R}{L}
\end{array}\right] *\left[\begin{array}{l}
i_{\alpha}(t) \\
i_{\beta}(t)
\end{array}\right]+\left[\begin{array}{cccc}
\frac{1}{L} & 0 & \frac{-1}{L} & 0 \\
0 & \frac{1}{L} & 0 & \frac{-1}{L}
\end{array}\right] *\left[\begin{array}{c}
u_{\alpha}(t) \\
u_{\beta}(t) \\
v_{\alpha}(t) \\
v_{\beta}(t)
\end{array}\right]} \\
& {\left[\begin{array}{c}
i_{\alpha}(t) \\
i_{\beta(t)}
\end{array}\right]=\left[\begin{array}{ll}
1 & 0 \\
0 & 1
\end{array}\right] *\left[\begin{array}{c}
i_{\alpha}(t) \\
i_{\beta(t)}
\end{array}\right]+\left[\begin{array}{llll}
0 & 0 & 0 & 0 \\
0 & 0 & 0 & 0
\end{array}\right] *\left[\begin{array}{c}
u_{\alpha}(t) \\
u_{\beta}(t) \\
v_{\alpha}(t) \\
v_{\beta}(t)
\end{array}\right]}
\end{aligned}
$$

Equation in dq-frame is spitted into two equations, representing the $\mathrm{d}$ and $\mathrm{q}$ components.

$$
\begin{aligned}
& u_{d}(t)=v_{d}(t)+i_{d}(t) * R+L * \frac{d i_{d}(t)}{d t}-\omega L i_{q}(t) \\
& u_{q}(t)=v_{q}(t)+i_{q}(t) * R+L * \frac{d i_{q}(t)}{d t}+\omega L i_{d}(t)
\end{aligned}
$$

These dynamic equations the STATCOM controller can be derived as shown in Fig.14

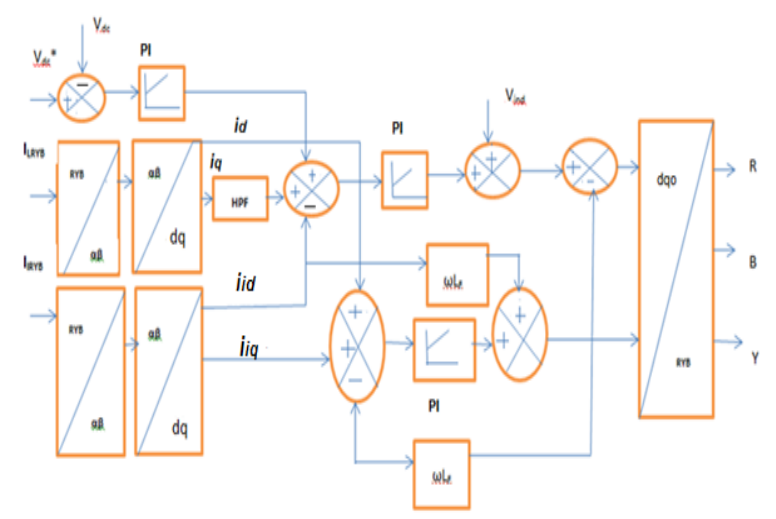

Fig. 13. STATCOM CONTROLLER

Copyright $($ ) Authors 224 


\section{Simulation of STATCOM}

The simulation of Voltage source controller is done for generation of switching pulses for STATCOM. Eventhough it is much tricky and expensive to implement directly controlled converter as compared to indirectly controlled converter. Indirectly controlled converter requires merely of rms current sensing at load point but the directly controlled converter requires measurement of rms current at load point and exhibits better dynamic performance.

\subsection{Analysis of Uncompensated system}

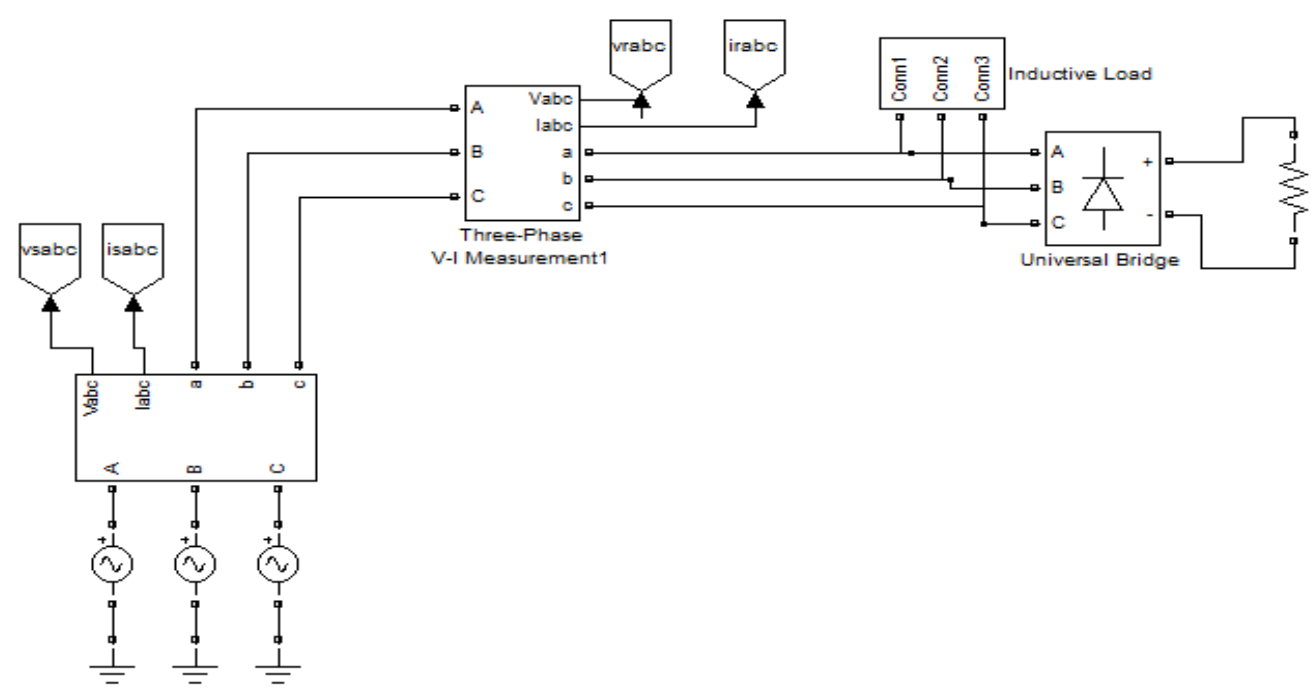

Fig.14. Simulation Schematic of Uncompensated System with Both Bridge Rectifier and Inductive load

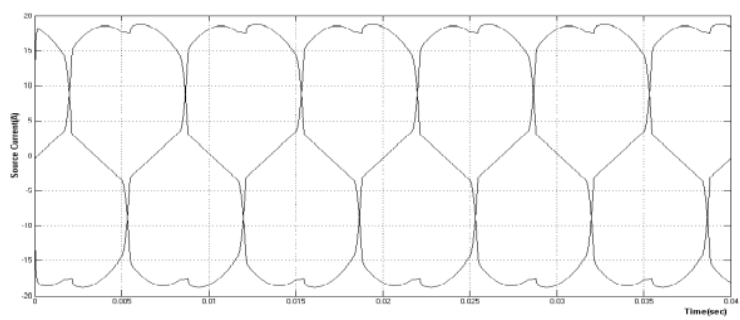

Fig. 15. Source Waveform of Uncompensated System with Both Bridge Rectifier and Inductive load

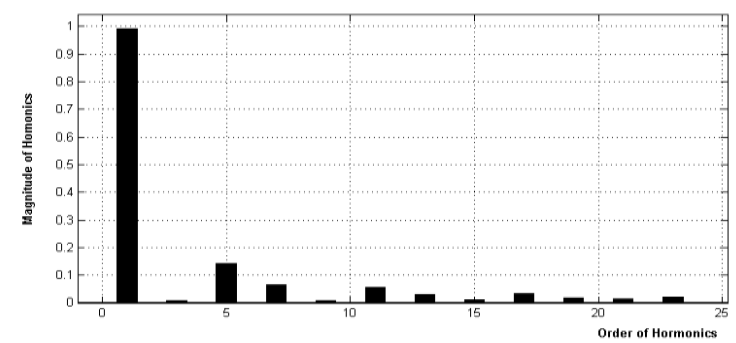

Fig.16. THD Spectrum of Both Bridge Rectifier and Inductive load

$\begin{array}{clcr}\text { Significant } & \text { Harmonic } & \text { Values } & \text { for } \\ \text { Uncompensated } & \text { System with } & \text { Both Bridge }\end{array}$

Copyright $\subset$ Authors
Rectifier and Inductive Loads as shown in below table 
Table 1. Uncompensated System Significant Harmonic Values

\begin{tabular}{|c|c|c|}
\hline SI.No. & $\begin{array}{c}\text { Significant } \\
\text { harmonics }\end{array}$ & $\begin{array}{c}\text { Values } \\
\text { (Relative of } \\
\text { Fundamental) }\end{array}$ \\
\hline 1 & $3^{\text {rd }}$ & $0.2 \%$ \\
\hline 2 & $5^{\text {th }}$ & $14.11 \%$ \\
\hline 3 & $7^{\text {th }}$ & $6.76 \%$ \\
\hline 4 & $9^{\text {th }}$ & $0 \%$ \\
\hline 5 & $11^{\text {th }}$ & $5.36 \%$ \\
\hline 6 & $13^{\text {th }}$ & $3.52 \%$ \\
\hline
\end{tabular}

Simulation of Uncompensated System with Bridge Rectifier and Inductive Load shows that the Source current has harmonic components and the significant harmonics values are given in table and the uncompensated System has a THD of $18.7 \%$ and the reactive power Requirement of $3.4 \mathrm{kvar}$ and has a power factor of $0.85 \mathrm{lag}$.

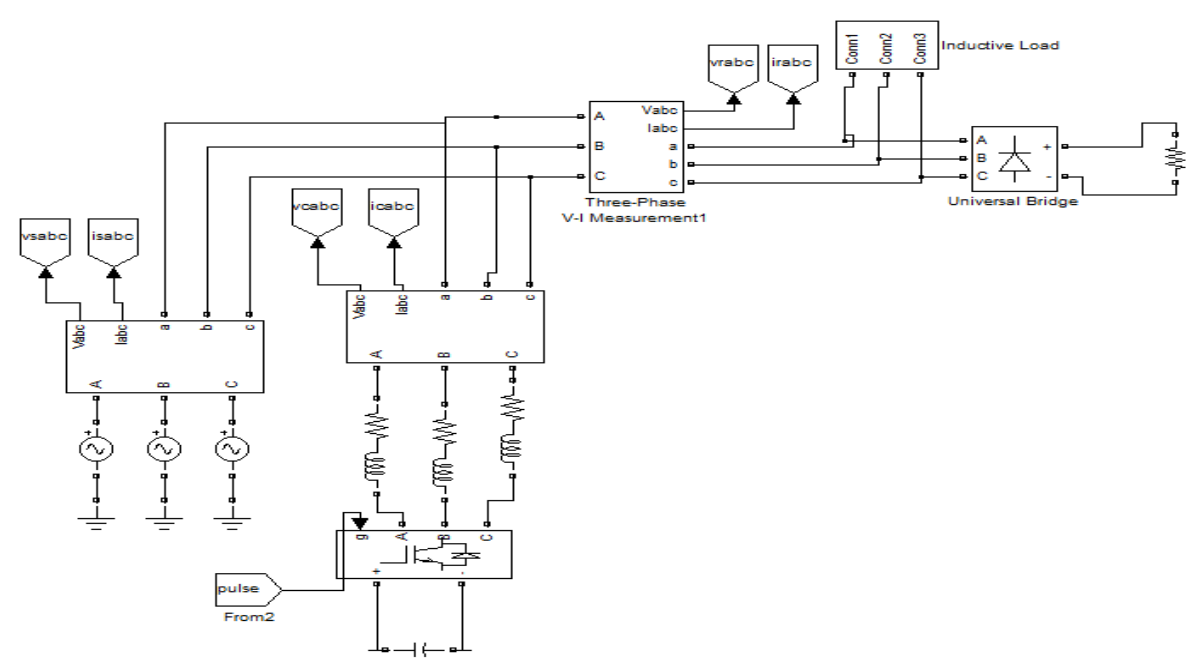

Fig.17. Simulation Schematic of Compensated System with Both Bridge Rectifier and Inductive load

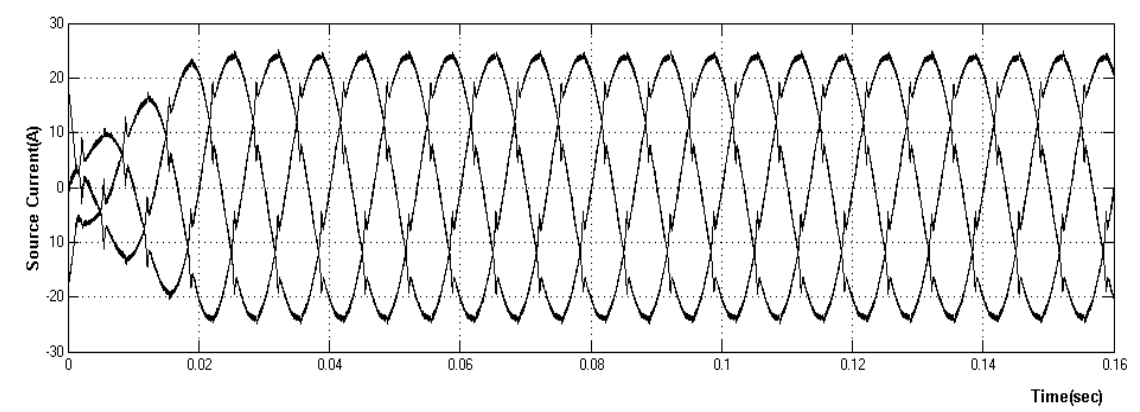

Copyright $($ ) Authors 
Fig.18. Source Current Wave Form after Compensation

The above source current wave form is the compensated current after the STATCOM connected in shunt to the uncompensated system.

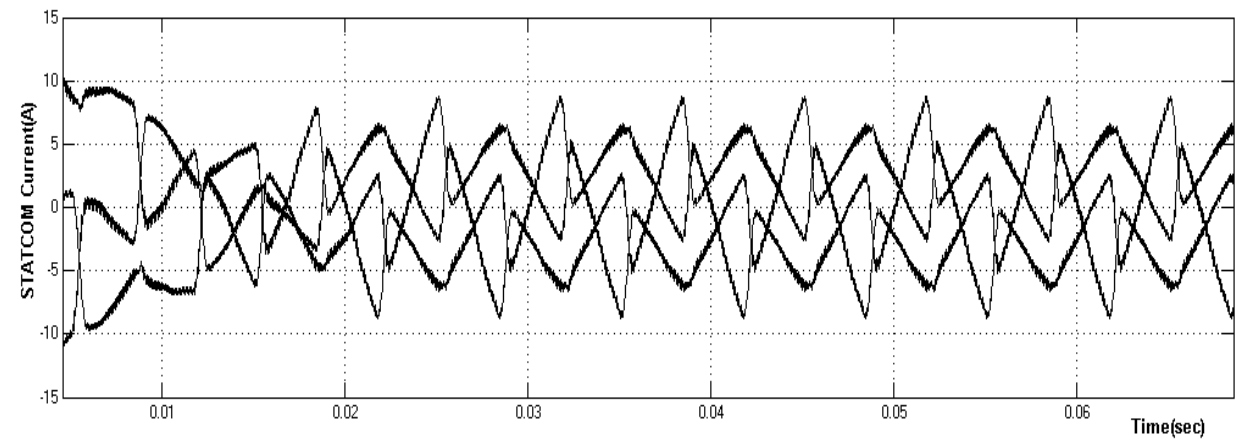

Fig. 19. Output Current of VSC

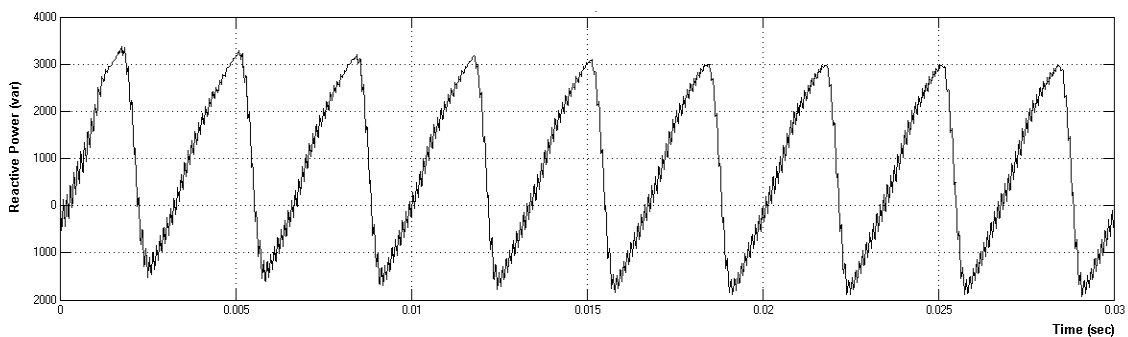

Fig.20. Reactive Power injected by the STATCOM

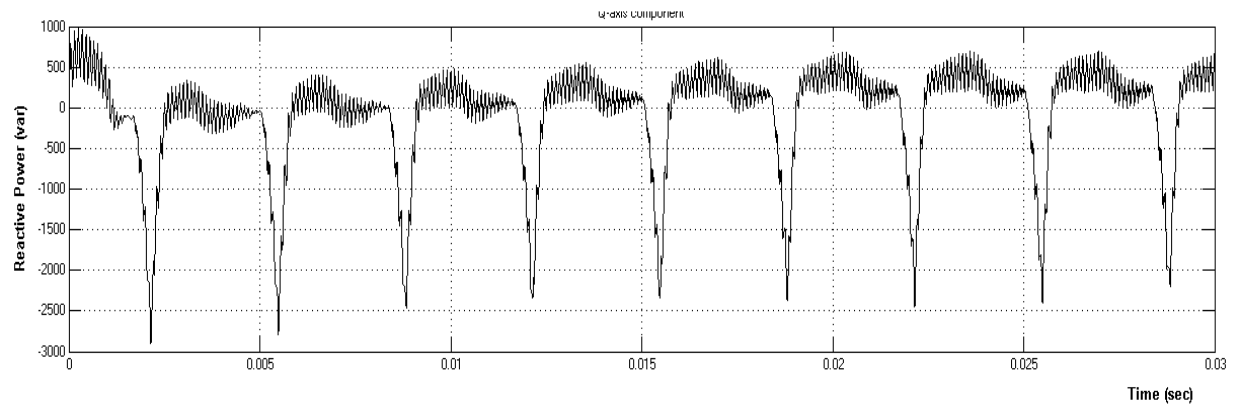

Fig. 21. Reactive Power from the Source 


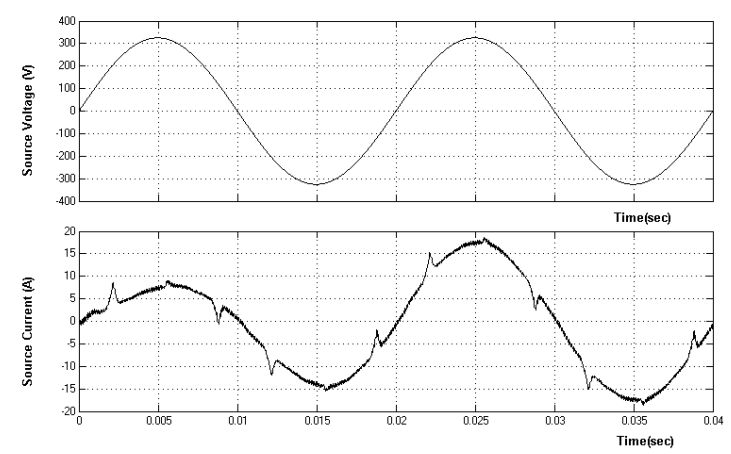

Fig.22. Source Voltage and Current Wave Form

These Source current and Voltage Waveforms shows no phase shift between voltage and current and the current wave form has less harmonic content and the power factor of this compensated system with both bridge and inductive loads is $0.95 \mathrm{lag}$.

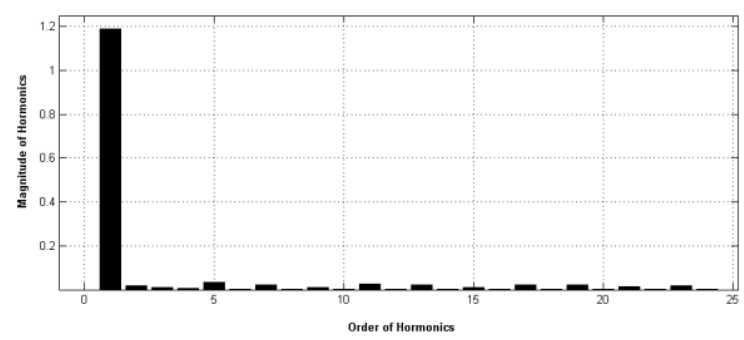

Fig. 23. THD Spectrum of the Source Current of a Compensated System

Significant Harmonic Values for compensated System with Both Bridge Rectifier and Inductive Loads as shown in below table.

Table 2. Compensated System Significant Harmonic Values

\begin{tabular}{|c|c|c|}
\hline SI.No. & $\begin{array}{c}\text { Significant } \\
\text { harmonics }\end{array}$ & $\begin{array}{c}\text { Values } \\
\text { (Relative of } \\
\text { Fundamental) }\end{array}$ \\
\hline 1 & $3^{\text {rd }}$ & $0.45 \%$ \\
\hline 2 & $5^{\text {th }}$ & $0.23 \%$ \\
\hline 3 & $7^{\text {th }}$ & $2.81 \%$ \\
\hline 4 & $9^{\text {th }}$ & $0.3 \%$ \\
\hline 5 & $11^{\text {th }}$ & $2.08 \%$ \\
\hline 6 & $13^{\text {th }}$ & $1.5 \%$ \\
\hline
\end{tabular}

Simulation of compensated system with bridge rectifier and inductive load shows that the source current is free from harmonic components and the significant harmonics values are less compare to the uncompensated System which are given in above table.

Copyright $@$ Authors

\section{Conclusion}

The modeling of the STATCOM controller is done by means of synchronous rotating frame theory. This controller is modeled in such way that STATCOM injects or absorbs the reactive power based on the dynamic load changes. The simulation is done by connecting a STATCOM 
in parallel to the uncompensated system. This project focuses on improvement of power quality in a three phase three wire system with a nonlinear load i.e., three phase bridge rectifier and a parallel inductive load. Some power quality aspects like reactive power compensation of linear load, the power factor improvement and better Total Harmonic Distortion (THD) performance is achieved.

\section{References}

[1] G. Yaleinkaya, "Characterization of Voltage Sags in Industrial Distribution Systems “, IEEE trans. Industry applications, vol. 12, no. 3, Oct. 1999.

[2] L.Gyugyi, "Application Characteristics of Converter Based FACTS Controller," in proc. IEEE, vol.76, n0.4, pp. 483-493, September 1988.

[3] Bhim Singh, Jitendra Solanki. "A comparison of Control Algorithms for STATCOM," IEEE trans. Industrial electronics, vol .56, no.7, July 2009.

[4] N.G.Hingorani and L.gyugyi,"Understanding FACTS Concepts and Technology of Flexible AC Transmission System, " IEEE press, 2000.

[5] Arindam Ghosh, "The Concept and Operating Principles of a mini Custom Power Park", IEEE trans. Power delivery, vol.56, no.2, pp. 12931298, July 2004.

[6] Bhim Singh,"A T-Connected Transformer and Three-Leg VSC Based STATCOM for Power Quality Improvement “, IEEE Trans. Power electronics, 2008.

[7] Walmir Freitas, "Impact of STATCOM Device on The Dynamic Performance of Distribution and Transmission Systems", IEEE trans. Power delivery, 2005.

[8] H. Akagi, "Proposed Terms and Definitions for Flexible AC Transmission System (FACTS)," IEEE Trans. power delivery, vol.12,no.4, pp.1848-1853, oct.1997.

[9] Ravindranath Tagore Yadlapalli, Anuradha Kotapati, A.R.Vijay Babu, Manoj Kumar.P, Modelling, Simulation and Control of Fuel cell Powered Laptop Computer Voltage Regulator Module, International Journal of Hydrogen Energy, 44, Issue 21, pp 11012-11019, $2019 . \quad$ DOI: https://doi.org/10.1016/j.ijhydene.2019.02.141

Copyright $($ ) Authors
[10] Polamraju.V.S.Sobhan, M.Subba Rao, N. Bharath Kumar, A.Sriharibabu, "FastConverging MPPT Technique for Photovoltaic System using Synergetic Controller", Journal of Mechanics of Continua and Mathematical Sciences, Vol.14, No.6, pp.582-592, 2019. 